\title{
Short Term Trend of Vegetation Removal Estimation by Aerial Photograph Analysis and Flood Flow Simulation
}

\author{
Deen Islam, Yuji Toda, and Tetsuro Tsujimoto
}

\begin{abstract}
This study purposes to estimate the spatial distribution of vegetation removal on a gravel bed and braided river, called the Tenryu in Central Japan. Aerial photograph and flood flow simulation are used to observe the vegetation change. High annual flood flow promotes vegetation removal and low flood flow in the preceding year accelerates vegetation invasion. Numerical simulation of flood flow can estimate the spatial conditions of vegetation wash out or vegetation remaining with minor misjudgment. Inclusion of sediment transport equation in the simulation may reduce the misjudgment during computation.
\end{abstract}

Index Terms-Bed shear stress, drag force, flood flow, vegetation.

\section{INTRODUCTION}

In many Japanese rivers, dams were constructed mainly for flood control and efficient use of water resources. The impact of these dams regulated the flow but reduced the degenerative capacity of river. As a result, vegetation inside the river develops and covers the bar. The new vegetation not only reduces the flood capacity in the downstream [1] but also increase the water stage in the rivers. In general, the flood disturbance frequency, flood intensity and bed degradation due to flooding and sediment particle size are considered to be important factors that affect the vegetation community. Therefore it is important to understand the washout condition of riparian vegetation due to floods. Drag moment acting on the plant [2] or bed shear stress [3] is a common hydrodynamic parameter to evaluate the washout condition of plants by floods.

A number of studies have been performed to know the effects of the riparian vegetation on flow characteristics and sediment transport [4]. Recently the washout condition of plants has been investigated by using 2-dimensional numerical simulation model for small spatial (1 or 2 bars) and small temporal (1or 2 floods) scale [5]. However, the aerial photograph method and numerical simulation method for examining the wash-out condition for relatively larger spatial and temporal scale has not been done together in the previous research. In this paper, both the aerial photograph method and numerical simulation method will apply to elucidate the washout condition of vegetation and finally, investigate the spatial locations of vegetation washed out and not washed out bar areas during flood flow in the main channel.

Manuscript received May 15, 2013; revised July 2, 2013.

D. Islam, Y. Toda, and T. Tsujimoto are with Dept. of Civil Engineering, Nagoya University, Furo-cho, Chikusa-ku, Nagoya 464-8601, Japan (e-mail: deenislam77@gmail.com, ttsujimoto@genv.nagoya-u.ac.jp).

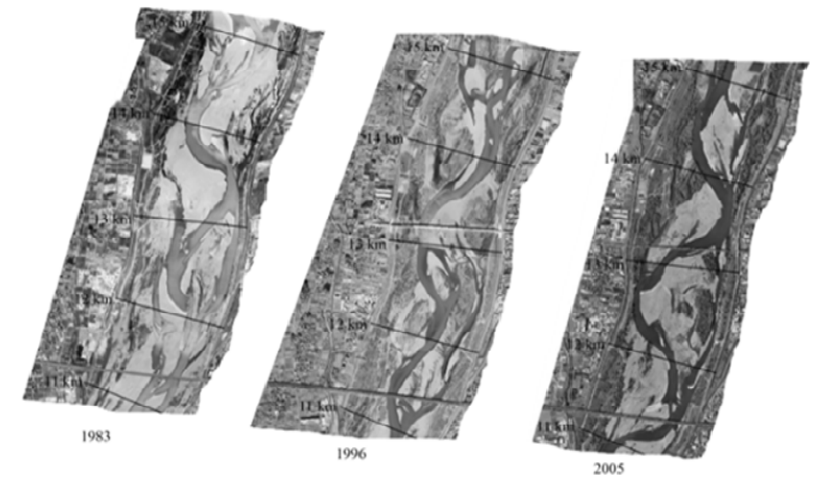

Fig. 1. Aerial photograph of the Tenryu river downstream (11-15 km from river mouth), Sizuoka Prefacture, Japan.

\section{THE TENRYU RIVER AND STUdy REACH}

The Tenryu is one of the Japan's largest rivers. Its catchment area and total length of main watercourse are $5,090 \mathrm{~km} 2$ and $213 \mathrm{~km}$, respectively. This study focuses on the braided reach of the Tenryu river, located between 9 to 21 $\mathrm{km}$ upstream from the river mouth. Fig. 1 clearly shows that, as time progressed, the river flood plain area increased and the river transformed from a multiple bar braided to an alternate bar meandering in nature. It also shows a positive trend of vegetation invasion in the bar and flood plain areas for the time being. The average slope and river width of the study reach are $1 / 700$ and $900 \mathrm{~m}$, respectively. The average median particle size and $\mathrm{d} 85$ ( $85 \%$ of particles finer than this size) are 20.5 and $49.7 \mathrm{~mm}$, respectively.

\section{AERIAl Photograph ANALysis}

\section{A. Flood Flow and Vegetation Change}

Flood magnitude as well as flood frequency have direct impact on vegetation change in the river channel. Vegetation invasion goes high in low magnitude flood year and vice versa. In contrast, more vegetation destruction occurs during high magnitude in a year and higher frequency increases the chances of vegetation destruction. Fig. 2 plots the relation between annual maximum flood flow, annual flood frequency and percentages of vegetation invasion and destruction for the available image years.

In Fig. 2, the highest vegetation invasion (15.84\%) is observed in 1996 and the lowest (4.41\%) in 1983. It was reported that the very low flood intensity in the previous four years from 1992 to 1996 led high vegetation invasion. On the other hand, high magnitude floods in 1982 and 1983 gave the lowest vegetation invasion. Highest vegetation destruction was seen in 1998 and 2003 and the lowest in 1995. It was 
found that, in 1998, floods characterized by low magnitude but high frequency accelerated the highest vegetation destruction. In 2003, one high magnitude flood flow including two low floods led the highest vegetation destruction.

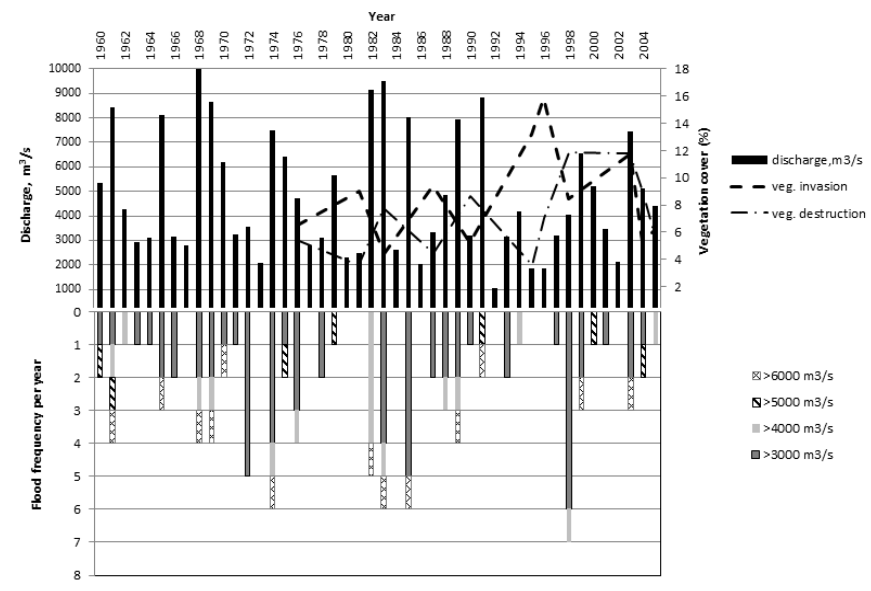

Fig. 2. Relation between annual maximum flood flow, flood frequency and the vegetation cover change in the Tenryu River for the period of 28 years. Image data is available from 1976 whereas hydrological data records from 1960 .

\section{B. Spatial Distribution of Vegetation Change}

Spatial distribution of vegetation expansion is presented in Fig. 3 which shows the highest vegetation expansion in 2003. It is also noticed that more vegetation has been settled in the middle bar area in the twentieth century than the previous period. Washed out of vegetation by maximum annual flood flow is the important issue to be discussed. Spatial locations of vegetation washed out are depicted in Fig. 4. This plot demonstrates the highest vegetation removal distribution during the period of 1995-1996. The extent of remaining vegetation is rather complicated than the previous two phenomena as it depends on several factors, such as hydrological and geomorphological conditions and the locations of vegetation parcels in the river area and flood plain. After the year 1995, remaining vegetation in the river channel stabilized and the year 2004 showed the highest remaining vegetation in the given period (Fig. 5). First, remaining vegetation was found in the river side area which then expanded to stabilize in the bar area during the period of 1998-2004.
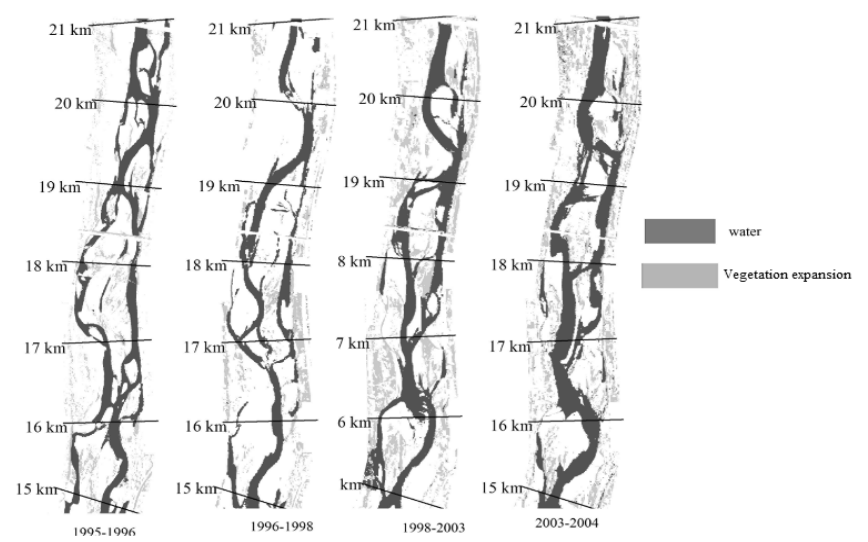

Fig. 3. Spatial distribution of vegetation expansion spatially for the different years in the Tenryu river downstream.
In Fig. 6, comparative vegetation expansion, washed out and remaining has been plotted in $\mathrm{m}^{2}$ for different years. Here, the year 2003 shows the highest vegetation expansion $(307.8$ $\left.\times 10^{4} \mathrm{~m}^{2}\right)$ followed by $2004\left(231.1 \times 10^{4} \mathrm{~m}^{2}\right)$ and $1995(217.2$ $\left.\times 10^{4} \mathrm{~m}^{2}\right)$, respectively. The lowest vegetation expansion $\left(104.5 \times 10^{4} \mathrm{~m}^{2}\right)$ is found in the year 1987 . The highest washed out vegetation $\left(250 \times 10^{4} \mathrm{~m}^{2}\right)$ is figured out in the year 1996 followed by $2004\left(220.8 \times 10^{4} \mathrm{~m}^{2}\right)$. The year 1990 experienced the lowest vegetation removal of only $90.28 \times$ $10^{4} \mathrm{~m}^{2}$. The year 2004 shows the highest remaining vegetation area $\left(194.2 \times 10^{4} \mathrm{~m}^{2}\right)$, followed by the years 1995 $\left(109.1 \times 10^{4} \mathrm{~m}^{2}\right)$ and $2003\left(107.3 \times 10^{4} \mathrm{~m}^{2}\right)$. In contrast, the year 1987 shows the lowest remaining vegetation area $(54.6$ $\left.\times 10^{4} \mathrm{~m}^{2}\right)$.

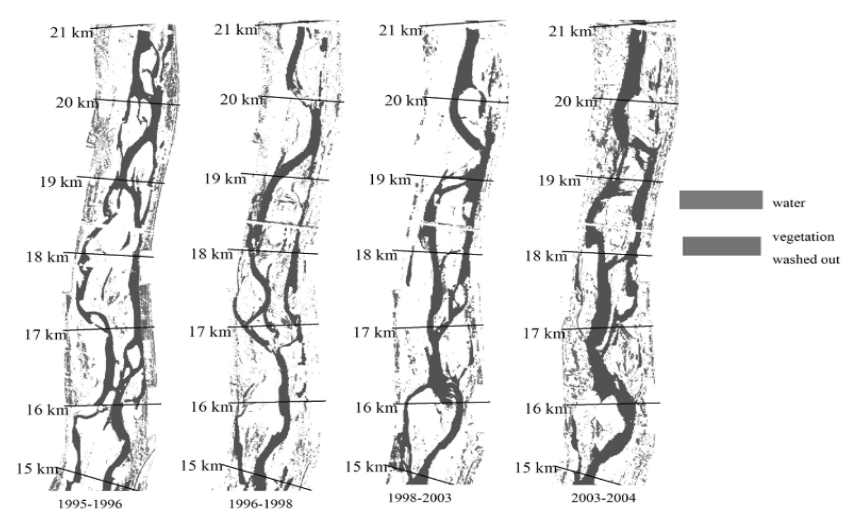

Fig. 4. Spatial distribution of vegetation washed out in different years in the Tenryu river downstream.

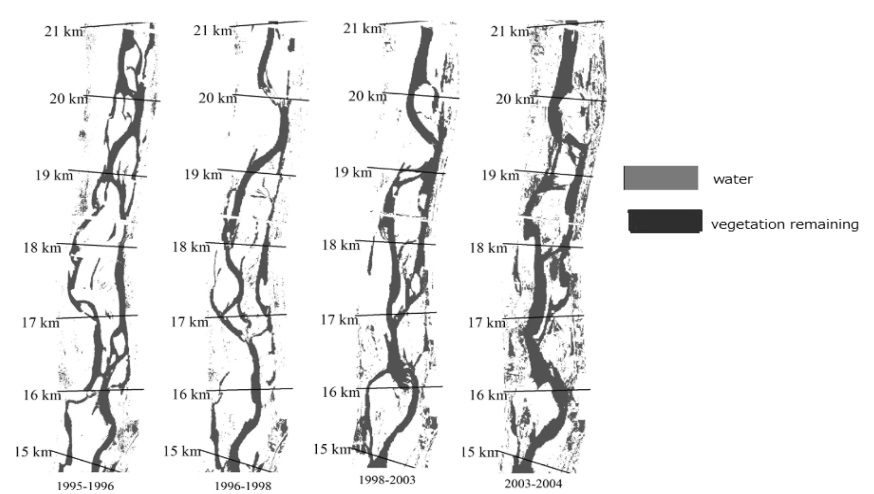

Fig. 5. Spatial distribution of vegetation remaining spatially for the different years in the Tenryu river downstream.

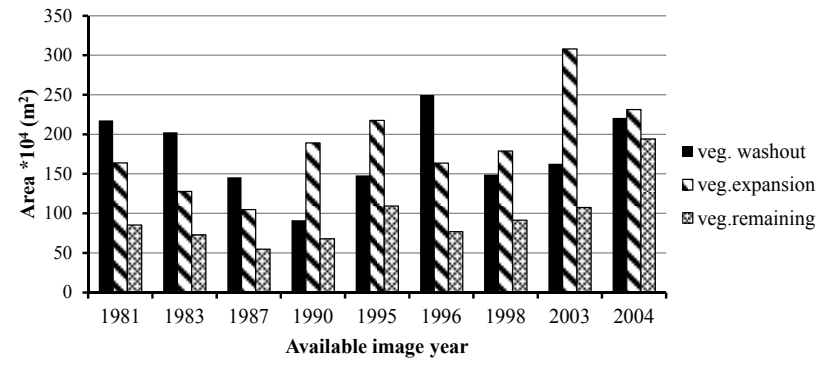

Fig. 6. Vegetation washed out, not washout and vegetation expansion has been given in $\mathrm{m} 2$ for the available image year.

To summarize, the vegetation washout, not washed out and vegetation invasion depend on the characteristics of flood flow and bar. First, high annual flood flow promotes vegetation removal and low flood flow in the preceding year accelerates vegetation invasion. Second, stable bar for some 
periods leads vegetation invasion followed by vegetation establishment in the bar areas.

\section{NUMERICAL ANALYSIS}

\section{A. Outline of Numerical Analysis}

To understand the relation between vegetation removal and hydraulic parameters (for instance, bed shear stress, drag moment, ratio of bed shear stress to dimensionless shear stress), steady state numerical analysis has been done for annual maximum flood discharge.

Two dimensional depth-averaged flood flow analysis using curvilinear coordinate system was carried out to predict the change in flow velocity and resistance to flow [6]. The Manning's roughness resistance law was used to determine the bottom friction [6]. The drag due to vegetation was determined by [7] and the depth-averaged kinetic energy was calculated from [8]. Determination of hydrodynamic parameter has been given in details in [9].

\section{B. Selection of Suitable Parameter}

As shown in Fig. 7, the wash-out condition of trees is evaluated by comparing aerial photograph and numerical analysis using drag moment and bed shear stress. According to [10], the critical shear stress for washing out trees was defined between the maximum shear stress at the vegetated area when trees were not washed out and the minimum shear stress when trees were washed out. Similarly, the critical moment for washing out trees was defined between the maximum moment where trees were not washed out and the minimum moment when the trees were washed out. The average critical bed shear stress and drag moment were taken by averaging the upper and lower values and these were 77 $\mathrm{N} / \mathrm{m} 2$ and $3000 \mathrm{~N}-\mathrm{m}$, respectively. Dotted vertical line indicates the threshold moment $(3000 \mathrm{~N}-\mathrm{m})$ and solid horizontal line indicates the threshold bed shear stress (77 $\mathrm{N} / \mathrm{m} 2$ ) for washing out trees. Overall, closed symbol indicates the vegetation washed out and the open symbol indicates the vegetation not washed out. In Fig. 7, the section a) indicates the numerical grid points fulfill both critical shear stress and critical drag moment; the section b) indicates the numerical grid points exceeding only the critical moment; the section c) defines the grid points not fulfilling any of the threshold values and the section d) indicates the numerical grid points satisfy the critical bed shear stress only. About $77 \%$ of selected numerical grid points show the vegetation removal satisfying both the threshold parameters. On the other hand, about $7 \%$ of selected numerical grid points washed out either satisfied the threshold shear stress or drag moment only. It can be said that both the parameters of numerical simulation can describe the washout condition of trees within the selected threshold. From Fig. 7, it is observed that the magnitude of drag moment has a broad range than that of bed shear stress. The critical moment for washing out trees on a bar of large diameter gravel is many times higher than that of sandy bar [10]. Therefore, uniquely threshold bed shear stress can better describe the washed out condition of trees in the gravel bed river during flood. It is worth mentioning that if the river bed materials around a tree are compacted or highly cohesive and have high critical shear strength for entrainment, the wash-out condition of trees is decided by the shear stress and the moment acting on trees.

\section{COMPARISION OF NUMERICAL ANALYSIS AND AERIAL PHOTOPGRAPH APPROACH}

Fig. 7 shows vegetation washed out or vegetation remaining conditions for the arbitrarily selected numerical gird cells which give scattered points information only. Therefore, in Fig. 8 and Fig. 9, spatial distribution of vegetation washed out and vegetation remaining scenarios have been presented for both the aerial photograph analysis and numerical simulation. For aerial photograph analysis, spatial location of vegetation washout and remaining has been selected by comparing two consecutive image years. Vegetation remaining means that vegetation exists both the image years and vegetation washout means vegetation present in the previous year and removed in the later year by flood flow. For numerical simulation plots, wash out of vegetation figured out when bed shear stress and drag moment were greater than their critical values, and vegetation remaining was shown when bed shear stress and drag moment were less than the critical values.

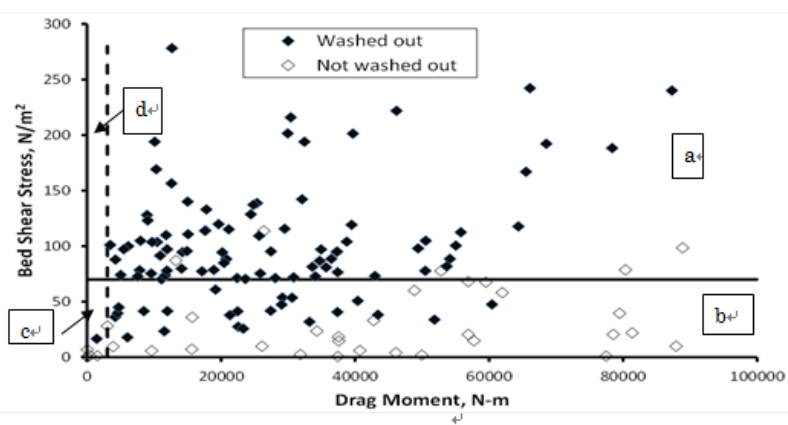

Fig. 7. Relationship between moment acting on trees and bed shear stress during different years flood flow. Closed symbol indicates trees were washed out and open symbol indicates trees were not washed out.

Fig. 8 shows the vegetation washed out and remaining scenarios of 1982 using flood simulation (right) and aerial photograph for the period of 1982-1983 (left). Two plots in Fig. 8 show that numerical simulation can estimate the vegetation washed out area spatially. In particular, the sections around 12 and 9-10 km have shown good estimation of washed out areas. Not washed out areas in the section, 13-14 km have been located precisely by numerical simulation.

In Fig. 9, vegetation washout and remaining are shown for the year 2003 where vegetation spreads in the middle bar and side bar areas. Comparing the plots in Fig. 9 shows that most of the middle bar washed out vegetation is properly estimated in numerical simulation. For instance, middle bar vegetation washed out in the section around 12 14 km has been figured out properly. In case of side bar vegetation, washed section around $13 \mathrm{~km}$ (left side) is properly simulated. Moreover, most of the not washed out vegetation existing in the flood plain is also reflected in the numerical simulation. However, still some locations show discrepancy between aerial method 
and numerical simulation. For instance, remaining vegetation area is over estimated in the section $9-10 \mathrm{~km}$ and washed out area is over estimated in the section around $13 \mathrm{~km}$ during simulation.

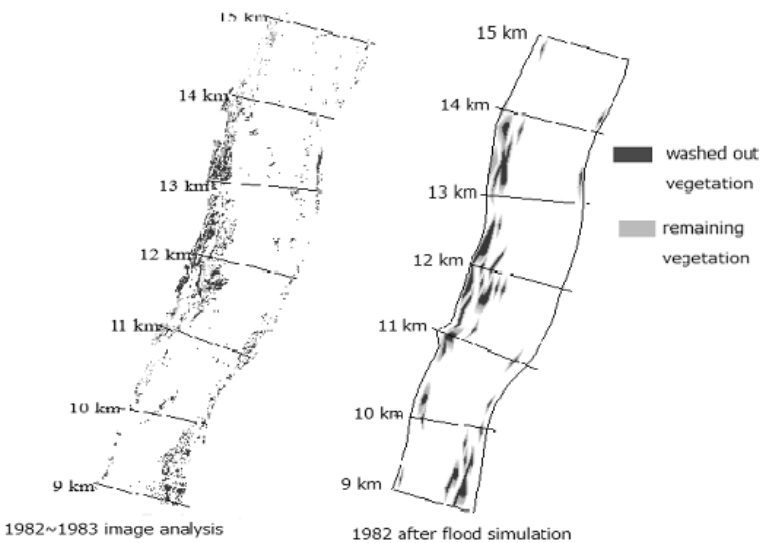

Fig. 8. Comparison of vegetation remaining and washout conditions from aerial photograph analysis and numerical simulation. Left figure represents the vegetation washed out or not washed out conditions by aerial photograph during 1982 1983. Right figure plots the vegetation washed out or not washed out conditions obtained from 1982 annual maximum flood flow numerical simulation (good approximation).

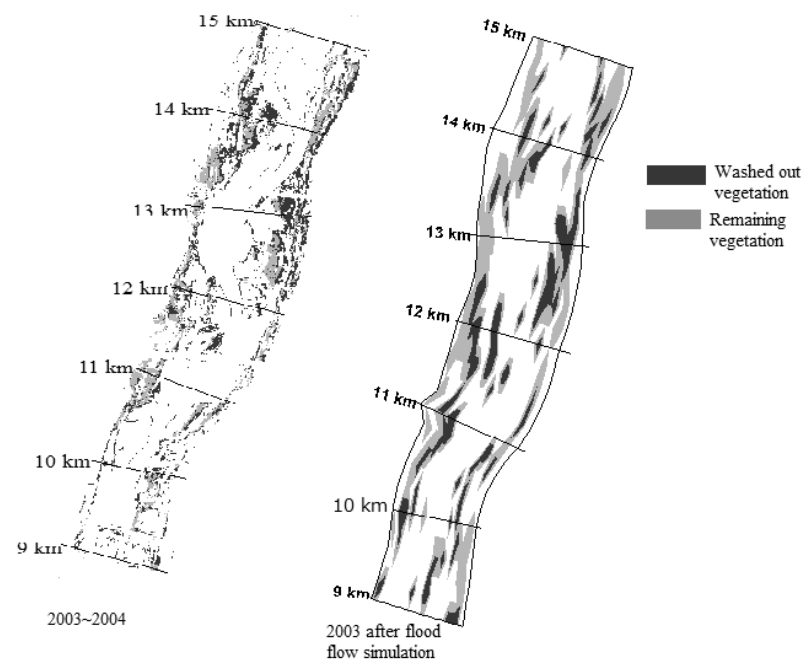

Fig. 9. Comparison of vegetation remaining and washout conditions from aerial photograph analysis and numerical simulation. Left figure represents the vegetation washed out or not washed out conditions by aerial photograph. Right figure plots the vegetation washed out or not washed out conditions obtained from numerical simulation (fair approximation) of 2003 annual maximum flood flow.

Overall, it is possible to estimate vegetation washed out or vegetation remaining conditions spatially by flood flow numerical simulation. However, some grid cells show misjudgment which can be discussed as a) numerical simulation has very coarse resolution of computation (like $200 \mathrm{~m} \times 30 \mathrm{~m}, \mathrm{~b}$ ) assumed empirical parameter in numerical simulation may not fit well with local condition; and c) absence of sediment transport process in the numerical simulation. Furthermore, Tenryu river Authority has its own vegetation management including cutting the trees and removing sandbars which also affects the estimation of vegetation removal. Further approach to minimize the misjudgment and improve accuracy of simulation should include sediment transport bed load equation in the numerical simulation.

\section{CONCLUSION}

The aerial photograph analysis and flood flow numerical simulation were performed to estimate the vegetation removal area in the Tenryu river, and the result of the study have revealed the followings:

1) Maximum flood intensity as well as flood frequency are important parameters in the analysis of distribution of vegetation expansion and destruction.

2) Numerical simulation fairly estimates the vegetation washed out and not washed out conditions in the years 1982 and 2003.

3) Some over estimation and under estimation have been reported due to coarse resolution of the computation, and not including the sediment transport equation in the numerical simulation.

\section{ACKNOWLEDGMENT}

This research was supported in part by the Fund of Beautifying and Greening the Riverside Environment by the Foundation of River and Watershed Environment Management (FOREM), Japan, and by the JSPS KAKENHI Grant Number 24560620.

\section{REFERENCES}

[1] M. Righetti and A. Armanini, "Flow resistance in open channel flows with sparsely distributed bushes," Journal of Hydrology, vol. 269, pp. $55-64,2002$.

[2] B. Gardiner, H. Peltola, and S. Kellomäki, "Comparison of two models for predicting the critical wind speeds required to damage coniferous trees," Ecological Modelling, vol. 129, pp. 1-23, 2000.

[3] E. Egger, R. Benjankar, L. Davis, and K. Jorde, "Simulated effects of dam operation and water diversion on riparian vegetation of the lower Boise river Idaho, USA," 32nd IAHR Congress (CD-ROM), 2007.

[4] S. Ikeda and N. Izumi, "Width and depth of self-formed straight gravel bed river with bank vegetation," Water Resources Research, vol. 26, no. 10, pp. 2353-2364, 1990

[5] J. Yagisawa and N. Tanaka, "Differences of tree-breaking pattern and breaking moment by floods with different tree age and substrate condition under two flood disturbances," in Proc. 8th International Conference on Hydro-Science and Engineering, Nagoya, Japan, 2008, pp. $473-474$.

[6] Y. Toda, S. Ikeda, K. Kumagai, and T. Asano, "Effects of flood flow on flood plain soil and riparian vegetation in a gravel river," Journal of Hydraulic Engineering, vol. 131, no. 11, pp. 950-960, 2005.

[7] S. Ikeda, N. Izumi, and R. Ito, "Effects of pile dikes on flow retardation and sediment transport," Journal of Hydraulic Engineering, vol. 117, no. 11, pp. 1459-1478, 1991.

[8] I. Nezu and H. Nakagawa, "Turbulence in open-channel flows," in IAHR Monograph, Balkema, Rotterdam, the Netherlands, pp. 53-56, 1993.

[9] D. Islam, Y. Toda, T. Furukawa, and T. Tsujimoto, "Long term trend and removal condition of riparian vegetation in gravel and braided river- case of downstream reach of Tenryu river," International Review of Civil Engineering, vol. 3, no. 6, pp. 463-473, 2012.

[10] N. Tanaka and J. Yagisawa, "Effects of tree characteristics and substrate condition on critical breaking moment of trees due to heavy flooding," Landscape and Ecological Engineering, vol. 5, no. 1, pp. 59-70, 2009.

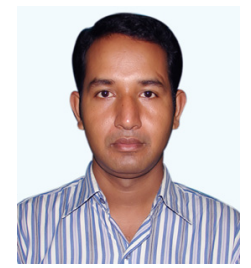

Deen Islam was born in Munshigonj, Bangladesh, on 28 July 1977 . He received B.Sc. in agricultural engineering, Bangladesh Agricultural University, Mymensingh, Bangladesh, in 2001; M.Sc. in hydrology and water quality, Wageningen University, The Netherlands, in 2010. Field of Study: hydrology and quantitative water management

He has published some journal papers. His current and future research field is river hydraulics. 


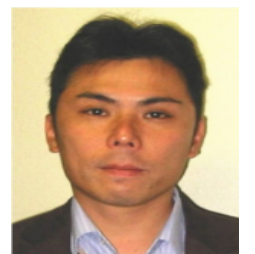

Yuji Toda was born in Kochi, Japan on 17 July 1972. He received B.Sc. in civil engineering, Tokyo Institute of Technology, Tokyo, Japan, in 1995;

M.Sc. in civil engineering, Tokyo Institute of Technology, Tokyo, Japan, in 1997; Doctor of Engineering, Tokyo Institute of Technology, Tokyo, Japan, in 2004 in water control science.

He has published a lot of papers. journal papers. His current research field is eco-hydraulics and future research interest is river environment.

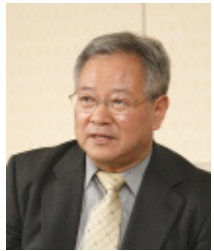

Tetsuro Tsujimoto was born in Nara, Japan, on 16 June 1949. He received B.Sc. in civil engineering, Kyoto University, Japan, in 1973; Doctor of Engineering, Kyoto University, Japan, in 1978 in water control science.

He has published lot of journal papers. His current research interest is river environment.

Dr. Tsujimoto is Japanese society of Civil Engineers (JSCE) and International Association for Hydro-environmental Engineering (IAHR). 